\title{
Review Editor's Introduction
}

\author{
By Jeffrey C. Isaac
}

$\square$ olitical science is a prolific profession. So much so that it is impossible for us to assign for review all the interesting books being written and published by our colleagues. The long-standing American Political Science Association convention for organizing the book reviews is by subfield. We have done nothing to interfere with this convention, which no doubt serves important functions. However, there are surely other ways to order or connect books, ways that perhaps have more intellectual warrant than the standard categories, which lack any real thematic content. So, prodded by my persistent assistants, we inaugurated an Editor's Comment to highlight some interesting themes among the books currently under review.

One broad theme, of obvious political importance in our world, is the problem of democratic inclusion in a world of difference, inequality, conflict, and porous borders. Our American Politics section features a review of two recent books (by Ron Hayduk and Stanley Renshon) on immigration and political incorporation and reviews of two other books (by Reuel R. Rogers and Sharon D. Wright Austin) on racial and ethnic exclusion and inclusion. Our Comparative Politics section also features four reviews of related books, on the incorporation of Islamic parties in Yemen and Jordan (by Jillian Schwedler), the challenges of secularism in Turkey (by Esra Ozyurek), ethnic politics in Latin America (by Donna Lee Van Cott), and multiculturalism and citizenship in Europe (by Ruud Koopmans et al.). Our International Relations section features a review of Susan Olzak's The Global Dynamics of Racial and Ethnic Mobilization, an account of transnational ethnic politics that also exemplifies the new work being done at the intersection of international relations and comparative politics. Finally, our Political Theory section includes reviews of three books that deal, in different ways, with the moral and legal challenges posed by the political regulation of difference-Daniel Carey's book on Enlightenment understandings of diversity, Nadia Urbinati's book on representation, and Wendy Brown's Regulating Aversion: Tolerance in the Age of Empire.
This is also the central theme of our featured review essay by Rogers Smith, which discusses a number of recently published books-by Carol A. Horton; Ira Katznelson; Theda Skocpol, Ariane Liazos, and Marshall Ganz; Richard M. Valelly; and Aristide R. Zolberg-on the important topics of race, ethnicity, and democratic inclusion in American political development (which is a burgeoning idiom of inquiry that in many ways straddles conventional subfield boundaries).

The negotiation and regulation of difference is clearly a pressing problem of our time, and it is heartening to read the above-mentioned reviews and books together and to contemplate the manifold ways that political scientists can contribute to a broad and rigorous scholarly dialogue that adds to our understanding.

Speaking of dialogue, this issue inaugurates another new practice- “conversational" reviews. It is striking how much specialization exists in our profession. Sometimes shaking things up a bit can produce interesting results and new and productive conversations. So, when we received books by Lawrence Baum - a premier scholar of judicial behaviorand Mark Graber - a premier scholar of public law- and we scoured our data base and our imaginations trying to come up with reviewers for them, I had an epiphany: What if I asked them to review the other's book, and then allowed each to write a short response? We could then create a real conversation between two important scholars in the same broad field-let us call it "law and society," not an "officially recognized" political science category—who, for reasons of subfield subspecialization, might not normally be regular scholarly interlocutors. I was lucky. Both Larry and Mark jumped at the chance, thinking it could be both interesting and enjoyable. Such an exchange can work productively only if both scholars are serious, substantive, and collegial. I think our featured exchange is a model of scholarly communication across methodological boundaries, and it demonstrates that when serious scholars are willing to go a bit beyond their "comfort zones," greater mutual understanding and intellectual progress is often the result. I hope you will agree. 